\title{
Hohhot Earthquake Emergency Shelter Planning and Construction Situation Analysis and Suggestion
}

\author{
Xiaoli Cui ${ }^{1}$, Zhifen Sun ${ }^{1}$, Narenmandula ${ }^{1, *}$, Zhuoligetu ${ }^{2}$, Jianzhong Zhang ${ }^{2}$ \\ ${ }^{1}$ College of Geographical Science, Natural Disaster Prevention Research Institute, Inner Mongolia Normal \\ University, Hohhot 010022, China \\ ${ }^{2}$ Earthquake monitoring and forecasting research center of Inner Mongolia Autonomous Region. Hohhot \\ 010010, China

\section{呼和浩特市地震应急避难场所 规划建设现状分析及建议} \\ 崔晓莉 ${ }^{1}$, 孙志芬 ${ }^{1}$, 那仁满都拉 ${ }^{1, *}$, 卓力格图 ${ }^{2}$, 张建忠 ${ }^{2}$ \\ ${ }^{1}$ 内蒙古师范大学地理科学学院, 内蒙古师范大学自然灾害防治研究所, 呼和浩特, 中国, 010022 \\ 2 内蒙古自治区地震局, 呼和浩特, 中国, 010010
}

\begin{abstract}
Reasonable planning and construction of emergency shelters is an important job for urban economic and social sustainable development, to ensure the safety of people's lives and property, it has very important significance for earthquake disaster reduction. This paper introduces the principle of planning and construction of earthquake emergency shelters, geological conditions of geography of Hohhot as well as emergency shelter planning and construction situation, and the construction of the status quo analysis, based on the Hohhot earthquake emergency shelter construction plan put forward the corresponding opinions and suggestions.
\end{abstract}

Keywords: earthquake emergency shelter; Planning and construction and the suggestion; Hohhot

\section{摘要}

合理规划建设应急避难场所是城市经济社会可持续 发展、保障人民生命和财产安全的一项重要工作,

*通信作者: 那仁满都拉, 男, 博士, 副教授, 1974 年生, nm2050@163.com
对于抗震减灾有极为重要的意义。本文介绍了地震 应急避难场所规划建设原则、呼和浩特市地理地质 条件以及应急避难场所规划建设现状, 并对建设现 状进行分析, 在此基础上对呼和浩特市地震应急避 难场所规划建设提出相应的意见和建议。

关键词: 地震应急避难场所; 规划建设与建议; 呼 和浩特市

1. 引言

我国是地震频发的国家之一, 地震是对我国可 持续发展具有巨大破坏性的自然灾害, 地震伤亡人 数占所有灾害的 $54 \%$, 是诸灾之首 ${ }^{[1]}$ 。2016 年 2 月 21 日《中共中央国务院关于进一步加强城市规 划建设管理工作的若干意见》中第十九条提出: 切 实保障城市安全。其中提到要提高城市综合防灾和 安全设施建设配置标准, 加强城市防灾避难场所建 设, 增强抵御自然灾害、处置突发事件和危机管理 能力 ${ }^{[2]}$ 。城市地震应急避难场所是震前预报发布后 或震时、震后为受灾群众提供应急疏散和临时生活 的相对安全的场所, 是城市总体规划、综合防灾规 划的重要对象。呼和浩特是内蒙古自治区首府, 随 着呼和浩特城市化进程的加快, 生活、生产等基础 设施规模迅速扩大, 市区人口和财富愈发集中, 城 市整体防灾功能远远落后于城市的经济发展和设 施建设。规划建设应急避难场所已成为维护呼和浩 特经济社会可持续发展、保障人民生命和财产安全 
的一项重要工作, 对于抗震减灾有极为重要的意义。 本研究经过对呼和浩特市区现有公园、广场、体育 场等公共场所进行统计, 并与现有地震应急避难场 所规划建设情况进行对比, 分析其存在的问题, 提 出了相应的建议, 为呼和浩特市综合防灾规划建设 提供参考价值。

\section{2. 应急避难场所的类型及规划原则}

\section{1 应急避难场所类型划分}

根据我国实情及地震应急避难工作的特点, 一 般将避难场所划分为三种类型: 紧急避难场所、固 定避难场所及中心避难场所 ${ }^{[3-4]}$ 。

紧急避难场所应为就近避难, 服务半径为 $500 \mathrm{~m}$ ，场地应该不小于 $2000 \mathrm{~m}^{2}$ ，一般选用居民住 宅附近的花园、小公园、广场及小绿地, 作为灾民 临时集合然后可转移到固定避难场所的过渡地带。

固定避难场所则属于集中避难, 服务半径控制 在 $2000 \mathrm{~m}$ 以内, 场所面积为 $2000-10000 \mathrm{~m}^{2}$, 选用 城市公共场所, 包括公园、广场、体育场、学校操 场及具备避难功能的建筑物等, 以供灾民较长期集 中生活然后提供救援。

中心避难场所为远程总体避难, 位于城市中心, 面积应大于 $100000 \mathrm{~m}^{2}$, 应设置防灾、救灾、医疗 卫生和伤员转运中心, 选用具备相应功能的公园或 者建筑物。

\section{2 地震应急避难场所规划原则}

按城市地震避难疏散场所的规划原则与要求 ${ }^{[5-6]}$, 我国地震应急避难场所规划主要以下原则执 行。

安全第一。地震应急避难场所不可设置在地震 活断层、岩溶塌陷区、矿山采空区、场地容易发生 严重液化的地区和重要次生灾害源。现有空间向应 急避难场所的转化, 必须先进行防灾减灾改造。

就近避难。地震应急避难场所应相对均匀地分 布在城市各区。通常情况下, 所有人员按规划确定 的避难所就近避难。

“平灾” 结合。城市地震应急避难场所, 平时 用于教育、体育、文娱和其它生活、生产活动, 由 避难场所的所有权人或者授权管理者管理, 临震预 报发布后或地震灾害发生时及灾后避难时转换为 应急避难场所。

综合防灾。城市规划部门应当综合制定地震应 急避难场所和避难疏散道路。

步行为主。居民到避难所一般步行而至。地震
灾害发生后, 城市道路会遭受不同程度的破坏, 且 道路上人多、车多, 城市道路甚至避难路线甚至都 很拥堵, 居民主要选择步行。

照顾灾害弱者。灾害弱者是指残疾人、老年人、 病患、孕妇和儿童。在规划建设应急避难场所时, 应考虑他们避难过程中出现的各种问题, 例如避难 道路的设计、便捷代步工具的开发、储备物资的供 应、避难引导人员的组织安排等。

\section{3. 呼和浩特市基本概况}

呼和浩特是内蒙古自治区首府, 地处蒙古高原 南部, 内蒙古自治区中部大青山南侧, 是内蒙古的 政治、经济、文化、科教和金融中心，呼包鄂城市 群中心城市, 被誉为 “中国乳都”。呼和浩特市城 区包括赛罕区、回民区、新城区和玉泉区四个主城 区, 建成区面积 259 平方公里, 人口 197.7 万 $^{[7]}$ 。

\section{1 呼和浩特市地理地质状况}

呼和浩特市是我国 47 个重点抗震设防城市之 一, 是地震重点监视 ${ }^{[8]}$ 。从地理位置来看, 呼和 浩特市位于地震强度和频度仅次于“青藏高原地震 区” 的 “华北地震区”。“华北地震区” 中银川-河 套地震带位于河套地区西部和北部的银川、乌、达、 磴口至呼和浩特的地 ${ }^{[1]}$ 。

从地质构造来看, 呼和浩特市地处华北断块西 北部, 有阴山和山西北部两大活动构造带, 地质构 造复杂, 新构造活动强烈, 新生代断陷、第四纪活 动断裂极为发育。受华北地震区北东向现代挤压应 力场影响, 地震活动频繁, 是华北地震区重要地震 活动带之一。呼和浩特市区主要有 3 条断裂带, 分 别是: 大青山山前断裂带、大黑河断裂带和城中断 裂带 ${ }^{[7]}$ 。

根据区域地震地质和地震活动性分析及数理 统计等方法的研究, 在以呼和浩特市为中心半径 320 公里范围内, 未来可能对呼和浩特市有一定地 震影响的潜在震源区有 10 个, 最大震级可达 6.0 -7.5 级, 震源深度大约为 $15-30$ 公里, 市区的地 震危险主要来自呼和浩特、萨拉齐两个潜在震源区 [9-10]。

\section{2 呼和浩特市现有公园广场绿地统计}

据内蒙古 2014 年统计年鉴不完全统计, 呼和 浩特市现有 25 个公园, 各区都有分布, 赛罕区有 满都海公园、仕奇公园、敕勒川公园、春度公园、 呼和浩特树木园、银杏园等; 回民区有青城公园、 乌兰夫公园、新华公园、滨河公园、扎达盖公园、 


\section{Risk Analysis and Crisis Response in Big Data Era (RAC-16)}

新钢公园、呼和浩特植物园; 新城区有公主府公园、 北郊公园、成吉思汗公园、苏雅拉公园、团结公园、 阿尔泰游乐园; 玉泉区有南湖湿地公园、菩提塔公 园、锡林公园、怡园等。

除公园以外, 呼和浩特市还有 18 个广场和 5 个体育场馆可以作为避难场所, 分别为新华广场、 大召广场、国际会展中心广场、呼和浩特市政府广 场、火车站站前广场、回民区政府广场、玉泉区政 府广场、新城区政府广场、成吉思汗广场、赛罕区 广场、金桥广场、五塔寺广场、伊利广场、蒙西文 化广场、民族集团嬉水广场、金地广场、如意广场、 东河广场和内蒙古赛马场、呼和浩特体育场、内蒙 古体育馆、呼和浩特体育馆、呼和浩特市人民体育 场。

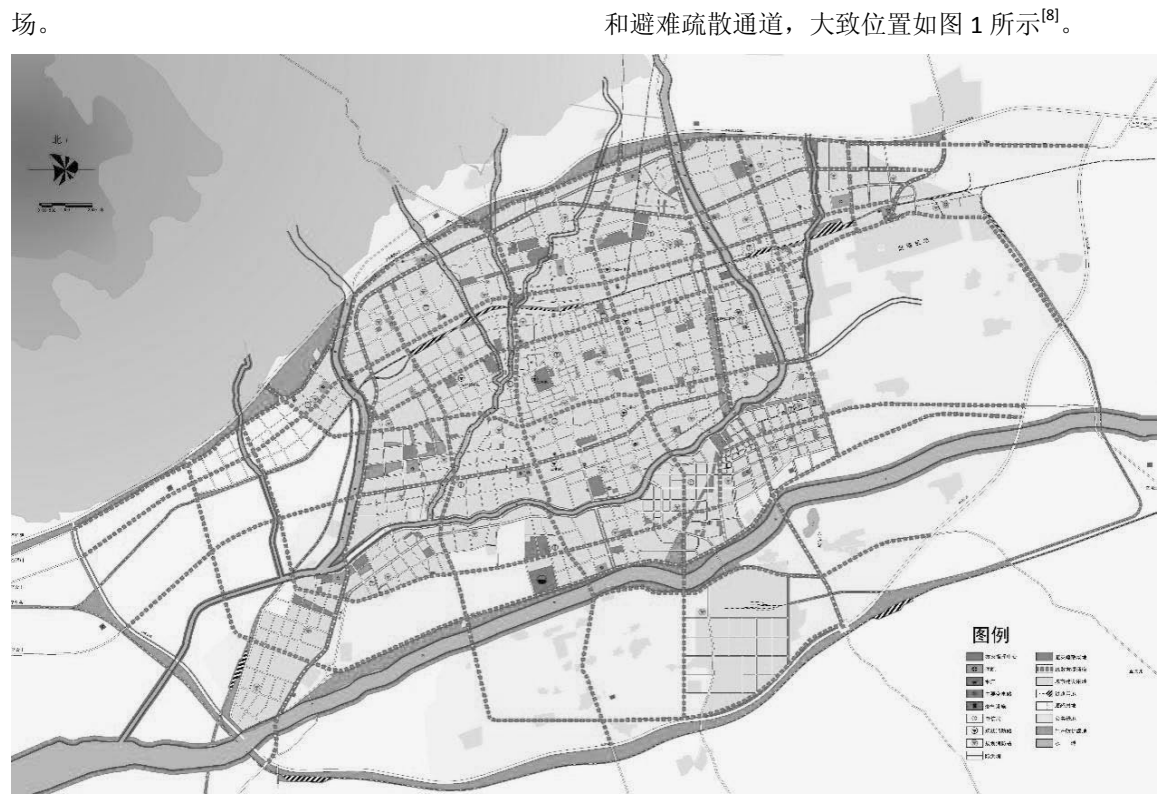

图 1. 呼和浩特市总体规划中的中心城区防灾规划
据媒体报道, 2014 年 6 月, 呼和浩特市地 震局组织召开了呼和浩特市地震应急避难场所 建设项目协调会, 就市内 4 区建设应急避难场 所的类别、数量、选址、建设内容进行了研究 分析。暂时确定的应急避难场所有 11 处, 分别 为: 新城区的阿尔泰游乐园; 回民区的青城公 园、回民区政府广场和扎达盖公园; 赛罕区的 敕勒川公园、满都海公园、金桥管委会广场和 春度公园; 还有玉泉区的玉泉区政府广场、菩 提塔公园和大召广场。该 11 个应急避难场所其 中有 6 个是总体规划中规划为避难疏散场所的,
另外, 内蒙古博物院以及内蒙古大学、内蒙古 师范大学、内蒙古农业大学、内蒙古工业大学、内 蒙古医科大学、内蒙古民族高等专科学校、内蒙古 财经大学等各大高校均有体育场馆可以作为避难 场所, 各中小学操场也可以作为避难场所临时避难。

\section{4. 呼和浩特市应急避难场所规划建设情况}

《呼和浩特市城市总体规划（2011－2020 年)》 中第十八章为中心城区综合防灾规划。文件中提到: 重视城市防灾减灾工作, 加强重点防灾设施和灾害 监测预警系统的建设，建立健全包括消防、人防、 防洪、防震和防地质灾害等在内的城市综合防灾体 系。其中第六点指出避难疏散, 包括避难疏散场所 和避难疏散通道, 大致位置如图 1 所示 ${ }^{[8]}$
但是还有 5 个在总体规划中并未划归避难疏散 场所，分别为回民区政府广场、金桥管委会广 场、玉泉区政府广场、菩提塔公园和大召广场。 该 11 个在建应急避难场所位置如图 2 所示。 截止目前, 以上 11 处应急避难场所最近 开始进场施工尚未建设完成, 效果尚不明显, 且施工过程中可能会遇到的问题也未可知。

\section{5. 规划及建设状况分析及存在问题 \\ 5.1 现有避难场所严重不足}

经计算, 若以上 11 处避难场所建设完毕, 有效棚宿面积大约 83 万 $\mathrm{m}^{2}$, 可容纳 42 万人临 


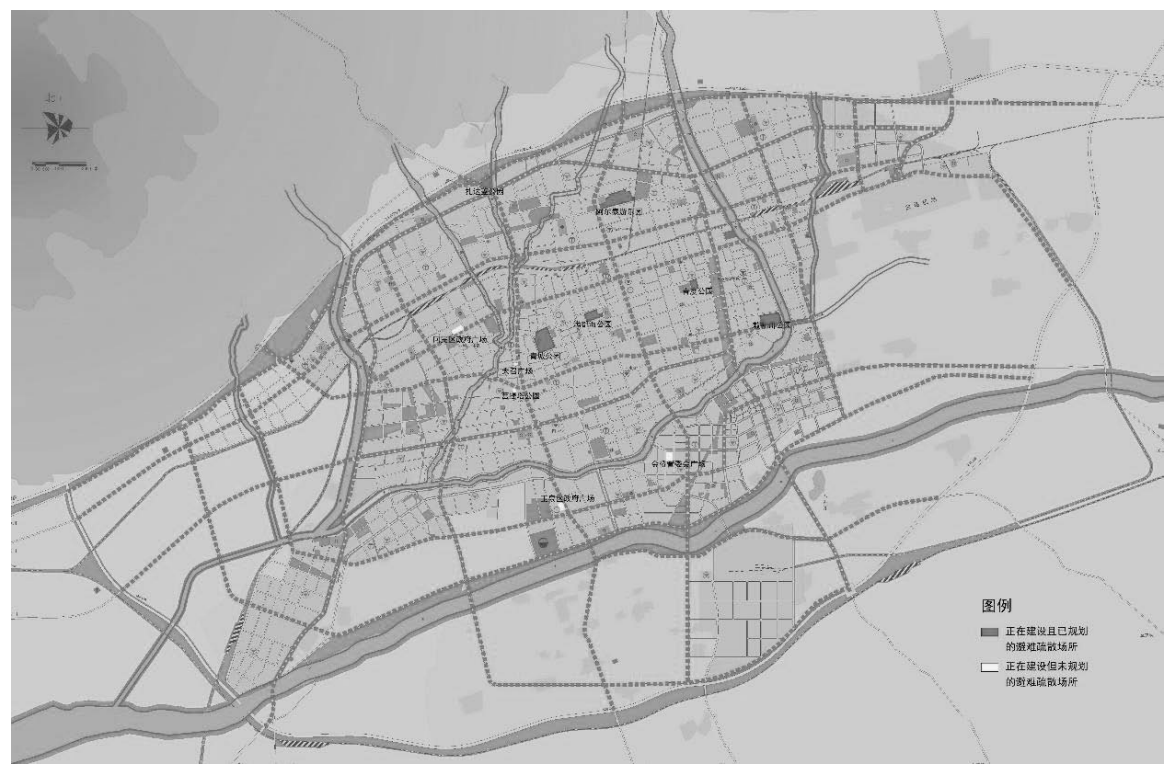

图 1. 呼和浩特市在建避难疏散场所

时避难，而呼和浩特市区人口 197.7 万，远远 不能满足所有市区人口的避难问题，且中部五 个避难所相对集中, 距离周边几个避难所较远, 分布不甚均匀; 经粗略统计, 呼和浩特市总体 规划中综合防灾规划中划定的避难疏散场所面 积大约为 530 万 $\mathrm{m}^{2}$, 按比例估算有效棚宿面积 大约为 410 万 $\mathrm{m}^{2}$, 若按照总体规划将规划的避 难疏散场所全部建设完成, 其数量基本可以满 足呼和浩特市区人口的避难所需。但是这只是 数量上的基本满足, 其配置均衡性与合理性仍 需进一步探讨。

\section{2 没有系统的地震避难场所规划}

从呼和浩特市总体规划来看, 在防灾规划 中将所有公园、广场、绿地、体育场以及中小 学高校操场甚至驾校场地都划归为防灾避难 场所, 但是并不能确定这些场地一定可以用来 作为避难场所使用。在城市总体规划中也就只 是粗略大致划取可利用地域, 并不能取代城市 防灾规划中对场地的勘测, 疏散道路以及各避 难场所面积、容纳人数、所在位置、服务半径 等详细的规划。目前还没有系统的防震应急避 难场所专项规划。

\section{3 现有应急避难设施獚乏}

呼和浩特市地震局虽然主持建设 11 处应 急避难场所, 但是仅仅在阿尔泰游乐场看到有 应急避难场所标志, 青城公园等其他现已确定 为应急避难场所的各公园广场并未布置与地 震应急避难相关的标志或告示牌, 且在道路两 旁也很少布置相关指示。地震应急避难场所缺 乏要求设置的配套设施, 包括临时用水、供电 照明、临时则所、通讯系统等 ${ }^{[11]}$ 。

\section{4 没有应急疏散道路规划}

呼和浩特市虽然计划建设 11 处地震应急 避难场所, 但是在避难场所周围没有进行应急 疏散道路的规划与设置, 一旦地震发生, 人流 车流没有正确引导, 容易引发交通拥堵, 造成 大量民众无法顺利抵达避难场所。

\section{5 防灾避震规划与知识宣传不足}

从实际情况来看, 市民对现有应急避难场 所几乎无所知晓, 大家也完全不知一旦发生紧 急状况第一时间应该奔向何地, 这说明政府相 关部门对此所做宣传与教育严重不足。同时, 市民对防震避灾相关知识也知之甚少, 缺乏地 震中自救以及避灾路线及场所的选择等相关 知识的了解。 


\section{Risk Analysis and Crisis Response in Big Data Era (RAC-16)}

\section{6. 加强呼和浩特市地震应急避难场所规划} 建设的建议

\section{1 进行系统的地震应急避难场所规划}

地震应急避难场所规划作为城市规划体 系中的一项专项规划, 应与城市规划相对应的 分阶段系统的进行规划 ${ }^{[12]}$ 。需要首先对城市各 区域进行地质勘测及抗震能力评估, 选择地质 条件优越, 地理位置合理, 抗震能力强的公共 场所及建筑作为地震应急避难场所进行规划 与建设。同时对城市地域及人口合理分配, 综 合考虑紧急避难场所、固定避难场所与中心避 难场所以及城市救灾指挥中心、医疗抢险中心、 抗灾物资储备仓库和各类交通方式运行及道 路的选址与规划, 逐个核定避难场所名称、面 积、服务半径、容纳人数及所在位置。在城市 规划图中, 明确绘制出各个避难场所具体位置、 避难通道以及与邻近避难场所的交通联系, 在 各避难场所内及周围道路设置引导性标示牌 及简易区划图。

\section{2 建立避难场所管理数据库}

在各避难场所规划建设过程中, 应该根据 实际情况建立一个城市避难场所数据管理平 台, 将各避难场所规划建设情况、周边人口数 量、可通达时间、设施状况、周边交通、疏散 路线及服务区域汇总在同一个数据库中, 便于 城市救灾指挥中心从整体出发全面协调引导 城市民众避难。为了数据信息的完善与精准, 应该定时对资料进行更新与补充。

\section{3 确保避难疏散道路通畅}

城市地震应急疏散道路作为震害发生后 受灾群众与各避难场所之间连接的纽带, 对抵 御地震灾害发生后引发的次生灾害及避灾救 灾过程有十分重要的作用。进行城市防灾规划 时要充分考虑避难疏散道路的合理布局与规 划建设, 将城市中各级避难场所连接形成网络 系统, 便于相互间物资人员等的转移。同时要 确保各应急避难场所的疏散通道在两个以上, 保持进入与撤出避难场所时的道路顺畅和交 通便利 ${ }^{[13-14]}$ 。

\section{4 加大地震应急避难知识宣传}

地震应急避难场所作为地震突发时群众 紧急避难的使用场所, 应该对广大市民积极推
广与介绍, 让城市居民了解震害发生时自己应 该前往的第一目的地 ${ }^{[15]}$ 。加强综合防灾减灾知 识的宣传教育, 增强全民防范意识, 在全市范 围宣传、普及防震减灾相关知识, 让普通市民 知晓防灾减灾的内容, 了解应急避难场所专项 规划。定期对市民群众进行避难相关知识培训 教育, 并发放地震应急逃生手册, 手册内标明 居住附近的避难场所与疏散路线, 节省逃生时 间, 使防灾规划应用到实际生活。同时, 利用 新闻媒体、社区公告、光盘播放、电视广告等 形式广为宣传, 普及避难场所的应用知识。

\section{5 结合实际, ${ }^{106}$ 平灾结合 ${ }^{m}$}

应急避难场所的规划和建设是以 “平灾结 合”、讲求经济效益为原则的 ${ }^{[16]}$, 在规划避难 疏散场所时, 应当从平、灾两个方面考虑其功 能, 平时用于教育、体育、文娱和其它生活、 生产活动, 临震预报发布后或地震灾害发生时 转换为避难疏散场所, 使休闲功能与避难功能 和谐统一, 相辅相成, 相得益彰。也为地震应 急避难场所的建设节省很大比例的成本, 有助 于经济城市、生态文明城市的建设与发展。

\section{7. 总结}

本文分析呼和浩特市地理地质条件以及 应急避难场所规划建设现状, 发现呼和浩特市 存在避难场所不足、避难设施贵乏、避难疏散 道路未规划且没有系统的防震避难规划等问 题, 并提出相应的意见和建议。本文存在的缺 陷与不足是由于到目前为止呼和浩特市还未 有避难所建设完成并投入使用, 文中未能做出 实际的案例分析。本人会在之后的研究工作中 深入探讨呼和浩特市地震应急避难场所的规 划与建设, 使呼和浩特市城市综合防灾规划的 内容更加详实。

\section{致谢}

本研究得到了国家自然科学基金项目 (41461101), 教育部留学回国人员资助项目, 内蒙古师范大学科研项目 ( YJRC12005, ZRYB1005）的资助。

\section{参考文献}

[1] 周长兴. 城市综合防灾减灾规划. 北京: 机械工业出版社，2011:39. 
[2] 中共中央国务院关于进一步加强城市规划 建设管理工作的若干意见，2016-02-21.

[3] 李刚, 马东辉, 苏经宇, 等. 城市地震应 急避难场所规划方法研究. 北京工业大学 学报, 2006 (10): 901-906.

[4] 吴志强, 李德华. 城市规划原理（第四 版). 北京: 中国建筑工业出版社, 2010: 9.

[5] 初建宇，苏幼坡. 城市地震避难疏散场所 的规划原则与要求。世界地震工程, 2006 (04): 80-83.

[6] 杜甫来. 地震应急避难场所规划建设的实 践与思考.中国地震学会第十次学术大 会. 中国北京, 2004: 1 .

[7] 2014 年呼和浩特市统计年鉴. 呼和浩特市 统计局, 2014.

[8] 呼和浩特市城市总体规划（2010-2020 年)。呼和浩特市人民政府，2011：05.

[9] 何仲太, 马保起, 卢海峰. 大青山山前活 动断裂带分段与潜在震源区划分. 地震地 质，2007（04): 765-775.
[10] J.P. Yan, S.S. Li, J. Bai, X.Y. Liu. The Spatial Symmetry Axis of Earthquake Hazard in China. Journal of Risk Analysis and Crisis Response, 2013, 3(1): 59 - 64.

[11] 林晨, 许彦曦, 佟庆. 城市应急避难场所 规划研究_以深圳市龙岗区为例. 规划师, 2007 (02): 58-60.

[12] 史亮. 北京市避震疏散体系的规划构建 一转型与重构, 2011 中国城市规划年 会. 中国江苏南京, 2011：12.

[13] 苏幼坡, 初建宇, 刘瑞兴. 城市地震避难 道路的安全保障. 河北理工大学学报 (社 会科学版)，2005，5(4)：191-193

[14] 郭莉莉, 隋明琦. 基于城市避难场所的疏 散通道规划布局研究--以大连市为例. 建 筑工程技术与设计，2014 (1): 6-6,8

[15] 吴小飞, 崔金东, 李旭. 秦皇岛市应急避 难疏散场所规划现状分析及建议. 甘肃科 技，2013（08）：4-5+65.

[16] 苏幼坡. 避难疏散场所规划. 现代职业安 全, 2009 (03): 86-88. 